Article

\title{
Discovery of Two Novel Negeviruses in a Dungfly Collected from the Arctic
}

\author{
Gang Lu, Zhuang-Xin Ye, Yu-Juan He, Yan Zhang, Xin Wang, Hai-Jian Huang, Ji-Chong Zhuo,

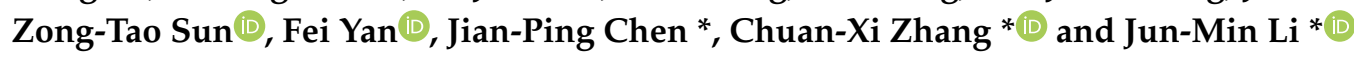

State Key Laboratory for Managing Biotic and Chemical Threats to the Quality and Safety of Agro-Products, Key Laboratory of Biotechnology in Plant Protection of Ministry of Agriculture and Zhejiang Province, Institute of Plant Virology, Ningbo University, Ningbo 315211, China; lugang@nbu.edu.cn (G.L.); yzx244522794@163.com (Z.-X.Y.); 15940518901m@sina.cn (Y.-J.H.); zhangxiaoli1028@163.com (Y.Z.); wangzhichaowork@163.com (X.W.); huanghaijian@nbu.edu.cn (H.-J.H.); zhuojichong@nbu.edu.cn (J.-C.Z.); ztaosun@gmail.com (Z.-T.S.); yanfei@yeah.net (F.Y.)

* Correspondence: jpchen2001@126.com (J.-P.C.); chxzhang@zju.edu.cn (C.-X.Z.); lijunmin@nbu.edu.cn (J.-M.L.)

Received: 26 May 2020; Accepted: 23 June 2020; Published: 27 June 2020

\begin{abstract}
Negeviruses are a proposed group of insect-specific viruses that can be separated into two distinct phylogenetic clades, Nelorpivirus and Sandewavirus. Negeviruses are well-known for their wide geographic distribution and broad host range among hematophagous insects. In this study, the full genomes of two novel negeviruses from each of these clades were identified by RNA extraction and sequencing from a single dungfly (Scathophaga furcata) collected from the Arctic Yellow River Station, where these genomes are the first negeviruses from cold zone regions to be discovered. Nelorpivirus dungfly1 (NVD1) and Sandewavirus dungfly1 (SVD1) have the typical negevirus genome organization and there was a very high coverage of viral transcripts. Small interfering RNAs derived from both viruses were readily detected in $S$. furcata, clearly showing that negeviruses are targeted by the host antiviral RNA interference (RNAi) pathway. These results and subsequent in silico analysis (studies) of public database and published virome data showed that the hosts of nege-like viruses include insects belonging to many orders as well as various non-insects in addition to the hematophagous insects previously reported. Phylogenetic analysis reveals at least three further groups of negeviruses, as well as several poorly resolved solitary branches, filling in the gaps within the two sub-groups of negeviruses and plant-associated viruses in the Kitaviridae. The results of this study will contribute to a better understanding of the geographic distribution, host range, evolution and host antiviral immune responses of negeviruses.
\end{abstract}

Keywords: negevirus; insect specific virus; virus evolution; small interference RNA

\section{Introduction}

Insect-specific viruses (ISVs) are those viruses that are confined exclusively to insects and which are unable to replicate in vertebrates or vertebrate cells [1]. ISVs have been largely overlooked for a long time because they do not cause disease in vertebrate hosts and usually have no economic impact on animals or plants. The recent rise of next generation sequencing and metagenomics has led to the discovery of a growing number of novel ISVs [2]. These have mostly been discovered in hematophagous insects, especially mosquitoes, as a result of a research into the risks that mosquito-borne viruses pose to the health of humans and domesticated animals [3]. Interestingly, the majority of ISVs are phylogenetically related to the classical arthropod-borne viruses (arboviruses) transmitted by mosquitoes. It has therefore been hypothesized that ISVs might be the ancestors of arboviruses and can act as natural regulators of the infection, replication and transmission of arboviruses [3,4]. Most ISVs 
can be recognized as members of the families of Bunyaviridae, Flaviviridae, Mesoniviridae, Reoviridae, Rhabdoviridae, Togaviridae, or a novel group described as negeviruses [1,5].

Negeviruses are ISVs with a non-segmented, positive-sense single strand RNA genome of about 9 to $10 \mathrm{~kb}$ and have been separated. They are usually assigned into two distinct phylogenetic clades named in the literature as Nelorpivirus and Sandewavirus [6] although these are not yet formally recognized taxa. Negevirus genomes are polyadenylated at their $3^{\prime}$ terminus and encode three open reading frames (ORFs) separated by intergenic regions. The largest, ORF1, is predicted to encode a polyprotein containing four domains involved in RNA replication: viral methyltransferase (vMet) domain; RNA ribosomal methyltransferase (FtsJ) domain; viral helicase (Hel) domain; and RNA-dependent RNA polymerase (RdRp) domain. ORF2 and ORF3 are believed respectively to encode a structural protein containing a predicted glycoprotein domain and a membrane protein, although little experimental evidence has been provided $[5,7,8]$. A previous study has suggested that the Ochlerotatus caspius negevirus (OCNV) can replicate in C6/36 cells (established from macerates of Aedes albopictus larvae) through the use of a double strand RNA (dsRNA) intermediate, which can be formed as early as $3 \mathrm{~h}$ after infection [9]. More recent small RNA analysis indicated that these dsRNA intermediates of nege-like viruses might trigger the small interfering RNA (siRNA) mediated antiviral pathway in the host insect [10].

The first study, in which six negeviruses were discovered from pools of mosquitoes and phlebotomine sand flies from 1977 to 2008, were collected in North and South America, Africa and Asia [5]. Since then, more negeviruses have been discovered worldwide, including the Tanay virus (TANAV) from the Philippines [11], the Okushiri virus from Japan [7], new strains of TANAV from China [12], the Goutanap virus from Côte d'Ivoire [6] in Africa, the Castlerea virus from Australia [13], the OCNV and Culex univittatus negevirus from Portugal [9], and the Wallerfield virus (WALV) from Brazil, Trinidad and Colombia [14,15]. These negeviruses have been from insects in tropical, sub-tropical and temperate regions between the latitudes $42^{\circ} \mathrm{N}$ and $42^{\circ} \mathrm{S}$ [16]. Most negeviruses have been identified from mosquito hosts, including nine genera within the family Culicidae, order Diptera [15]. Other potential insect hosts of negeviruses have included sandflies, bees, aphids, and fruitflies and they have also been found in some other animals such as nematodes, shrimps and mites [5,17-19], indicating that negeviruses may have a much broader host range than originally thought. However, the diversity of negeviruses in hosts other than hematophagous insects have not been well evaluated.

Phylogenetic analysis indicates that negeviruses are distantly related to plant-infecting viruses classified in the genera Cilevirus, Higrevirus and Blunevirus in the family Kitaviridae [15]. It has therefore been suggested that negeviruses and viruses in the family Kitaviridae might have originated from a common arthropod-infecting ancestral virus $[15,20]$ although the potential evolutionary pathway leading to host expansion has not been clearly elucidated.

In this study, the complete genomes of two novel negeviruses have been identified and characterized from a single non-hematophagous dipteran insect (dungfly, Scathophaga furcata) collected from the arctic. This expands the known host range and geographical distribution of negeviruses. Subsequent phylogenic analysis using other novel nege-like viruses from various insect hosts can provide new insights into the diversity of these viruses and the relationship between nege-like viruses and plant viruses. In addition, virus-derived small interfering RNAs (vsiRNA) were comprehensively investigated, suggesting that the host siRNA-mediated antiviral pathway might be involved actively against negeviruses.

\section{Materials and Methods}

\subsection{Sample Preparation and RNA Extraction}

A single dungfly-like adult insect was collected on July 2019 from Arctic Yellow River Station (Latitude: 78.9167, Longitude: 11.9333). The insect was captured alive and immediately transferred 
to RNA keeper tissue stabilizer (Vazyme, Nanjing, China) at low temperature $\left(4^{\circ} \mathrm{C}\right)$ and sent to our laboratory for RNA extraction. Total RNAs were extracted using TRIzol reagent (Invitrogen, Waltham, MA, USA) following the manufacturer's instructions and subdivided to provide samples for transcriptome (approximately $2 \mu \mathrm{g}$ ), small RNA (sRNA) (approximately $5 \mu \mathrm{g}$ ) and virus genome Sanger sequencing (approximately $5 \mu \mathrm{g}$ ).

\subsection{Transcriptome and sRNA Sequencing}

For transcriptome sequencing, ribosomal RNA (rRNA) was first removed from the total RNA using Ribo-Zero Gold rRNA Removal Kit (Illumina, San Diego, CA, USA) before preparing the sequencing library. Paired-end (150 bp) sequencing of the RNA library was performed on the Illumina HiSeq 4000 platform (Illumina, San Diego, CA, USA) by Novogene (Tianjin, China). The transcriptome reads were quality trimmed and assembled de novo using the Trinity software (Version 2.8.5) with default parameters [21].

The cDNAs of the sRNA library were prepared using the Illumina TruSeq Small RNA Sample Preparation Kit (Illumina, San Diego, CA, USA). sRNA sequencing was performed on an Illumina HiSeq 2500 by Novogene (Tianjin, China). Preliminary treatment of sRNA raw data (removal of adapter, low quality, and junk sequence) was carried out as described previously [22].

\subsection{Host Insect Identification}

To accurately identify the dungfly species, the assembled contigs from the transcriptome were compared using Blastn with all the available cytochrome oxidase subunit 1 (COI) barcode records from the Barcode of Life Data (BOLD) Systems (http:/www.boldsystems.org/) and the National Center for Biotechnology Information (NCBI) nucleotide (nt) database. The identified COI sequence of the dungfly was further confirmed by Sanger sequencing and submitted to GenBank with the accession number MT072894.

\subsection{Virus Discovery and Confirmation by Reverse Transcription-PCR (RT-PCR)}

To identify nege-like viral contigs, the assembled transcriptome contigs were compared to a nucleotide/protein database comprising representative negeviruses (Supplementary Table S1) downloaded from GenBank using BLAST+ (Version 2.9.0) and DIAMOND (Version 0.9.28.129). The e-value threshold for the comparisons was set at $2 \times 10^{-10}$. The candidate nege-like virus contigs were then extracted using home-made perl script based on the significance of the e-value and the matched length of the contig. To eliminate false positives, the candidate nege-like virus contigs were further compared with the entire NCBI nucleotide (NT) and non-redundant (NR) protein databases. RT-PCR was then performed followed by Sanger sequencing to confirm the presence of the two full nege-like virus contigs using the method described previously [22]. The primers used for RT-PCR are listed in Supplementary Table S2.

\subsection{Determination of Viral Genome Termini and Transcript Abundance}

To obtain the full length of the two identified negeviruses in the insect sample, the extreme $5^{\prime}$ and $3^{\prime}$ terminal sequences were determined by rapid amplification of cDNA ends (RACE) using the SMARTer ${ }^{\circledR}$ RACE 5'/3' kit (Takara, Beijing, China). After total RNA isolation, first-strand cDNA synthesis was performed to obtain 5'-RACE-ready and $3^{\prime}$-RACE-ready cDNA according to the manufacturer's instructions. Touchdown PCR was performed to amplify RACE products using $5^{\prime}$ or 3' GSPs (gene-specific primers) and UPM (Universal Primer A Mix). The PCR products were then cloned into the pMD19-T vector (Takara, Beijing, China) and further verified by Sanger sequencing. The primers used for RACE are listed in Supplementary Table S2. Based on the Blast search results, the two identified negeviruses were named Nelorpivirus dungfly1 (NVD1) and Sandewavirus dungfly1 (SVD1) and the sequences were submitted to GenBank with the respective accession numbers MT344120 and MT344121. 
To investigate the transcript abundance and coverage of the two identified negeviruses, the adaptorand quality-trimmed reads of the transcriptome were mapped back to the whole genome of NVD1 and SVD1 using Bowtie2 [23] and Samtools [24]. The coverage of the aligned reads to the virus genomes was further visualized using the Integrated Genomics Viewer [25].

\subsection{Genome Annotation}

Open reading frames (ORFs) of NVD1 and SVD1 were predicted by the ORF Finder online server (https://www.ncbi.nlm.nih.gov/orffinder/). Predicted conserved protein domains were identified using the Conserved Domain Database server [26]. Potential glycosylation sites were predicted using the NetNGlyc 1.0 Server (http://www.cbs.dtu.dk/services/NetNGlyc/). Transmembrane domains were analyzed by the TMHMM server v. 2.0 (http://www.cbs.dtu.dk/services/TMHMM/).

\subsection{Small RNA Analysis}

To identify siRNAs derived from NVD1 and SVD1, clean sRNA reads 18- to 30-nt long were extracted and collapsed using FASTX-Toolkit (http://hannonlab.cshl.edu/fastx_toolkit/). The processed reads were mapped to the assembled full genomes of NVD1 and SVD1 using Bowtie software allowing for zero mismatches [27]. Downstream analysis for the mapped vsiRNA was performed with custom perl scripts and Linux bash scripts, including size distribution of vsiRNA, vsiRNA distribution along the corresponding viral genome, and 5' terminal nucleotide preference of $21 \mathrm{nt}$ long vsiRNAs.

\subsection{Prevalence of Nege-Like Viruses Were Investigated in Invertebrates}

The prevalence of possible nege-like viruses in other hosts was investigated using the public Expression Sequence Tag (EST) and Transcriptome Shotgun Assembly (TSA) databases of NCBI. The putative protein sequences of representative known negeviruses (Supplementary Table S1) together with NVD1 and SVD1 were used as query, searching against the EST and TSA databases using tblastn. The potential novel nege-like viral contigs were then compared with the entire NCBI NT and NR databases to eliminate false positives.

\subsection{Phylogenetic Analyses}

Phylogenetic analysis used the amino acid sequences of the predicted RNA dependent RNA polymerase ( $R d R p)$ region of the newly identified nege-like viruses from this study, together with some previously described negeviruses from various hosts and plant viruses of the related families Kitaviridae and Virgaviridae. Sequences were obtained from NCBI, aligned using Muscle (Version 3.8.31) [28] and analyzed using the Maximum likelihood (ML) algorithm and the Jones-Taylor-Thornton (JTT) substitution model to construct a phylogenetic tree in MEGA X with 1000 bootstrap replications [29].

\section{Results}

\subsection{Negeviruses Identified in Dungfly}

A total of 84,181 contigs were generated from de novo assembly of the clean RNA-seq reads $(38,056,018)$. A Blast search among the COI sequences confirmed that the dungfly was Scathophaga furcata (Diptera: Scathophagidae). A BlastX search against the proteins of representative negeviruses suggested the presence of two potential new negeviruses. The nearly complete genomes of both were identified in the insect. One contig of $9212 \mathrm{nt}$ was identified as a nelorpivirus (NVD1), and was most similar to the Loreto virus (LRV, YP_009351835.1) with protein sequence identities of 69\%. The second contig (8858 nt), representing SVD1, was most similar to the sandewavirus Andrena haemorrhoa nege-like virus (AHNLV, YP_009553581.1) with identities of 55\%. A Blastn search against the NCBI NT database did not find any other sequences closely related to either NVD1 or SVD1, indicating that the two viruses are probably new negeviruses. The full genome sequences of both viruses were then verified by RT-PCR followed by Sanger sequencing and RACE to determine their $5^{\prime}$ and $3^{\prime}$ termini. 


\subsection{Genome Organization of NVD1 and SVD1}

The full-length sequences of NVD1 and SVD1 were respectively 9239 and $8894 \mathrm{nt}$ long excluding the polyA tail. The predicted genome organization of both viruses is typical of that reported for negeviruses with three major ORFs (Figure 1). ORF1 has the four conserved domains of the replication polyprotein (vMet, FtsJ, Hel and RdRP). N-glycosylation sites were predicted in ORF2 at amino acid positions 105, 138, 170, and 175 (NVD1), and positions 124, 161, 248, and 278 for SVD1. One (NVD1) or two (SVD1) transmembrane domains are present at the C-terminus of ORF2. While previously reported negeviruses and SVD1 have short intergenic regions between each of the ORFs, the ORFs 2 and 3 of NVD1 unusually overlap by $8 \mathrm{nt}$ and are in different frames (Figure 1A). Re-alignment of the RNA-seq reads to the reconstructed complete genomes of NVD1 and SVD1 show a very high mean coverage $(6858 \times$ for NVD1 and $8857 \times$ for SVD1), suggesting that the viruses replicate very efficiently in their host. Viral transcripts were very highly elevated in the $3^{\prime}$ region of the genome of both viruses (Figure 1).

(A)

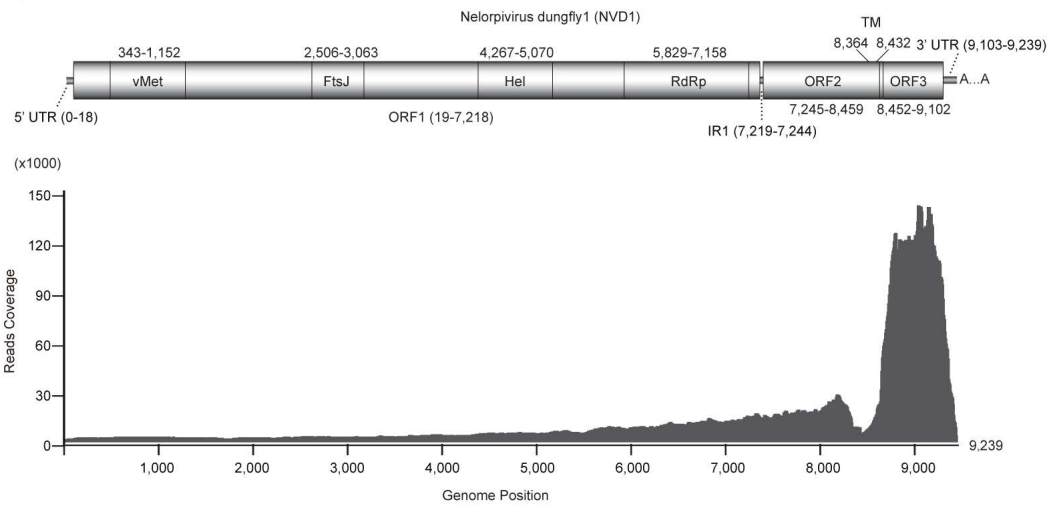

(B)
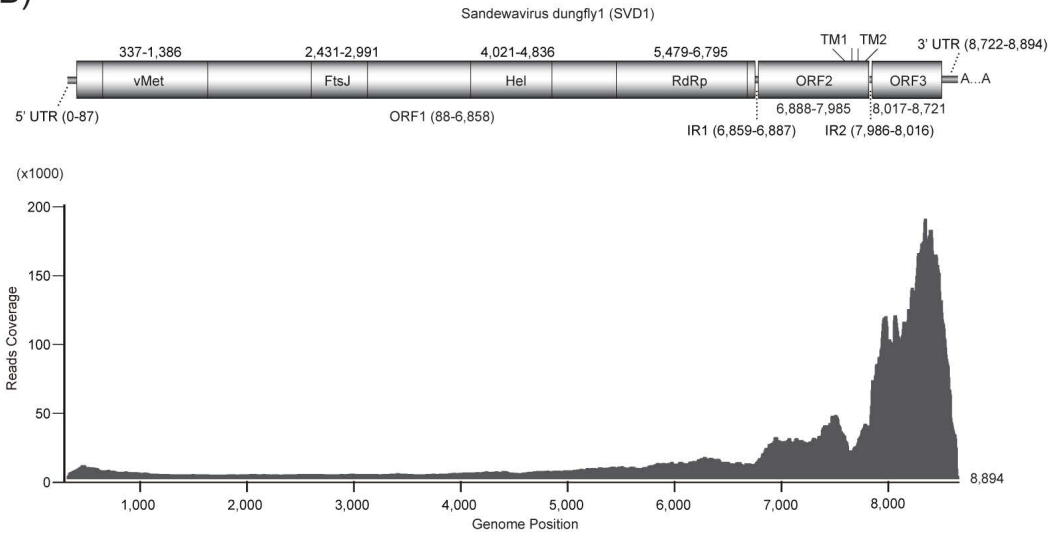

Figure 1. Genome organization and transcriptome raw read coverage of Nelorpivirus dungfly1 (A) and Sandewavirus dungfly1 (B). vMet, viral methyltransferase domain; FtsJ, RNA ribosomal methyltransferase domain; Hel, viral helicase domain; RdRp, RNA-dependent RNA polymerase domain; UTR, untranslated region; IR, intergenic region; TM, transmembrane domain; TM1 region, 7743-7811; TM2 region, 7872-7940.

\subsection{NVD1 and SVD1 Are Targeted by the Host siRNA-Based Antiviral RNAi Pathway}

siRNA-based RNA silencing is an important antiviral pathway in insects and is usually associated with the accumulation of vsiRNAs as viral RNA is degraded in a sequence-specific manner [30]. To better understand siRNA-based antiviral pathways in dungfly in response to negeviruses, we conducted a computational analysis of vsiRNAs in the sRNA library of $S$. furcata. A large number 
of siRNAs (18 nt-30 nt) derived from the two negeviruses were identified. A total of 68,717 sRNA reads $(16,995$ unique) mapped perfectly to the assembled genome of NVD1, accounting for $0.25 \%$ (1.65\% unique) of the whole sRNA library. The corresponding vsiRNA reads for SVD1 totaled 38,672 (11,053 unique), accounting for $0.14 \%$ (1.07\% unique) of the library. Most of these vsiRNAs were $21 \mathrm{nt}$ long (69.5\% and $70.1 \%$ of the totals for NVD1 and SDV1, respectively) and they were equally derived from the sense and antisense strands of the viral genomic RNA (Figure 2A,D), which are similar to the recent report [10]. The vsiRNAs were derived from the entire genome of both viruses including the untranslated regions, but there were notable asymmetric hotspots on both strands, suggesting that these regions might be preferential targets of the host immune system (Figure 2B,E). The viral siRNAs of both viruses had a strong A/U preference in their $5^{\prime}$ terminal nucleotide (Figure 2C,F), which is typical of vsiRNAs from various organisms, including insects [22,31]. These characteristics provide strong evidence that the antiviral RNAi pathway of dungfly is actively involved in response to negevirus infection.

(A)

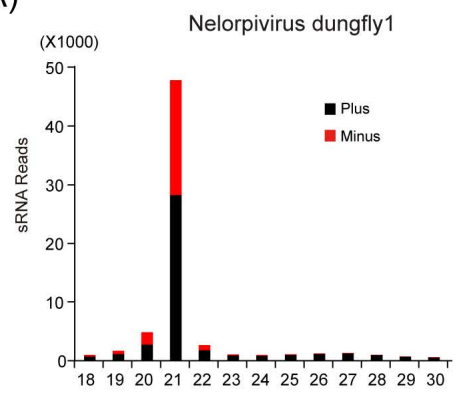

(D)

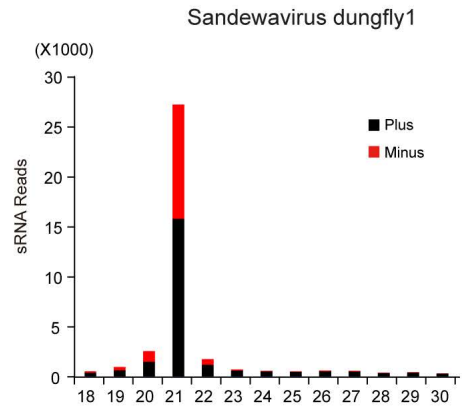

(B)

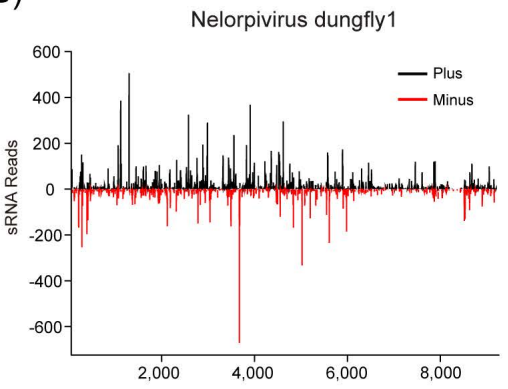

$(\mathrm{E})$

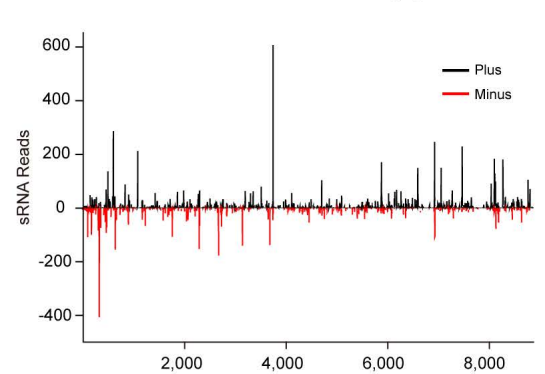

(C)

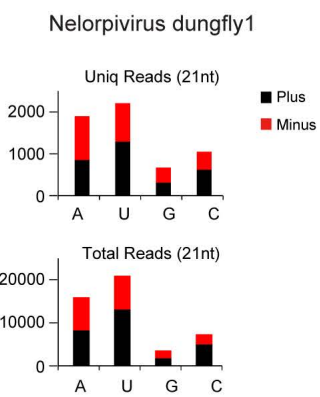

$(\mathrm{F})$

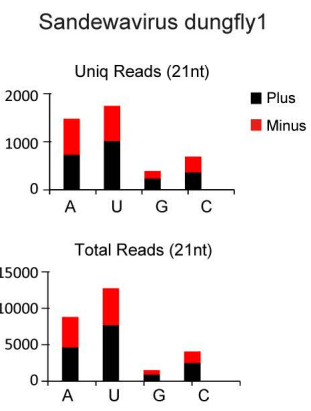

Figure 2. Profiles of virus-derived small interfering RNAs (vsiRNAs) of Nelorpivirus dungfly1 (NVD1) and Sandewavirus dungfly1 (SVD1). (A) Size distribution of NVD1 sRNAs. (B) Distribution of NVD1-derived sRNA along the corresponding viral genome. (C) 5' terminal nucleotide preference of sRNAs $21 \mathrm{nt}$ long derived from NVD1. (D) Size distribution of SVD1 sRNAs. (E) Distribution of SVD1 derived sRNA along the corresponding viral genome. (F) $5^{\prime}$ terminal nucleotide preference of sRNAs $21 \mathrm{nt}$ long derived from SVD1. Color coding indicates viral sRNAs derived, respectively, from the sense (plus) and antisense (minus) genomic strands.

3.4. The Presence of Further Nege-Like Virus Sequences in Public Databases Suggests That They Occur in Many Different Insects

Negeviruses are well-known for their wide geographic distribution and broad host range but most of the well-described ones have been isolated from hematophagous insects such as mosquitoes and sandflies $[3,15]$. The identification of NVD1 and SVD1 in a different type of insect and from a much colder environment prompted a search for other, potentially new, nege-like viral sequences, within the current public databases. Seven potentially new negeviruses were identified in the TSA database originating from firefly, flower thrips, sucking bugs, and various fruit fly species, suggesting a diversity and prevalence of insect hosts for nege-like viruses in nature (Table 1). In addition, reanalysis 
of previous virome studies confirmed that the hosts of negeviruses are broader than insects (Table 2). Within Insecta, and in addition to the Diptera, hosts of negeviruses included representatives of Hemiptera, Coleoptera, Thysanoptera, Odonata, and Orthoptera. Another four classes of the Arthropoda were also represented, including three species in Arachnida, one species in Malacostraca, one species in Maxillopoda, and one species in Chilopoda. Outside the arthropods entirely were two species in Nematoda and one species in Cnidaria [19,32]. We also have unpublished data [33] from a field investigation in 2019, which identified three nege-like viruses in whitefly (Bemisia tabaci) and one in grasshopper (Metaleptea brevicornis), and the sequences of viral RdRP regions were submitted to NCBI GenBank with accession number as listed in Table 2. It is clear that negeviruses are common in Insecta generally and not just in hematophagous insects.

\subsection{Putative New Phylogenetic Clades and Host Diversity of Negeviruses in Invertebrates}

A phylogenetic tree was constructed using sequences of negeviruses from various hosts and those of closely related plant viruses. NVD1 clusters with two LRV isolates and some other insect viruses in the previously identified Nelorpivirus clade, while SVD1 falls clearly with AHNLV and other insect viruses in the Sandewavirus clade (Figure 3). The topology of the tree also confirmed the close relationship of plant viruses in the family Kitaviridae that was previously reported $[11,15,16]$. Using plant viruses of the family Virgaviridae as an out-group, a number of other obvious groups of nege-like viruses can also be recognized. These include a branch with three insect viruses (Abisko virus, Adelphocoris suturalis virus, and Negelikevirus fruitfly3) and at least three other groups formed with high bootstrap value (labelled Group 1, Group 2, and Group 3 in Figure 3). There are also other several poorly resolved solitary branches for nege-like viruses. Although the Nelorpivirus and Sandewavirus clades are mostly viruses from the order Diptera within Insecta (mostly mosquitoes), there are also hosts in the orders Hemiptera (whitefly), Hymenoptera (bee), and from outside insects (house centipedes and spiders) from various regions of the world. Group 2 contains two closely related nege-like viruses, Sanxia atyid shrimp virus 1 and Beihai anemone virus 1, that are from hosts classified in different phyla (Arthropoda and Cnidaria) but from a similar ecological niche. 
Hosts

- Diptera (mosquitoes) - Diptera (dungfly...)

- Hemiptera (whitefly...)

- Coleoptera (firefly)

Thysanoptera (flowerthrips)

- Hymenoptera (bee)

- Odonata (odonata)

Orthoptera (grasshopper)

- Lepidoptera (moth)

- Besides insects (spider...)

- Besides arthropod (nematode...)

- Plants

${ }_{86}$ Culex Negev EO-329-like virus/Culex sp./USA/AX004834.1 86 Negev virus/Culex quinquefasciatus/USA:Harris Co.TWJAFI24684.1 99 Culex Negev \#730-like virus/Culex sp./USA/AXQ04831.1. 93 Negev-like virus/Ochlerotatus caspius/unknown/CCV01575. Ngewotan virus/mosquitoe unknown/Nepal/AQM55320.1 91 Manglie virus/Culex tritaeniorhynchus/China/QBR99594.

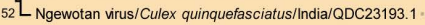

Culex negev-like virus 2/Culex australicus/Australia:Point Douro/YP_009388582.

99 Castlerea virus/Ochlerotatus clelandi/Australia/AQZ55393.1.

- Ying Kou virus/Culex pipiens pallens/China/YP_009552739.1 Daeseongdong virus 1/Culex pipiens/South Korea:Daeseongdong/YP_009182191.

99 Negevirus Nona 1/Aedes sp larvae/Japan:Hokkaido Okushiri island/BAS69360.1

Piura virus/Culex nigrioalpus/USA/AOM55337. 1 .....

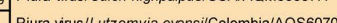

9 San Bernardo virus/mosquito-unknown/Colombia/AQM55296.

99 Brejeira virus/Culex sp/Brazil:Para State/AQM55484.1

${ }_{42}$ - Brejeira virus/Culex sp./Brazil:Para State/YP_009270625.

Big Cypress virus/Anopheles atropos/USAYYP_009351821.1

Nelorpivirus dungfly $1 /$ Scathophaga furcata/Arctic Yellow River Station/MT344120

Loreto virus/Anopheles albimanus/Peru/YP_009351835.1

99 Loreto virus/Lutzomyia sp./Peru/AFI24693.1

Wuhan house centipede virus 1/Scutigera coleoptrata/China/YP_009342435.

Negelikevirus whitefly $3 /$ Bemisia tabaci/China:Anhui/MT344124

- Negelik ins wit

Negelikevirus whitefly 2/Bemisia tabacilChina:Anhui/MT 344123 Saiwaicho virus/Drosophila suzukiilJapan/AWA82269.1 ....
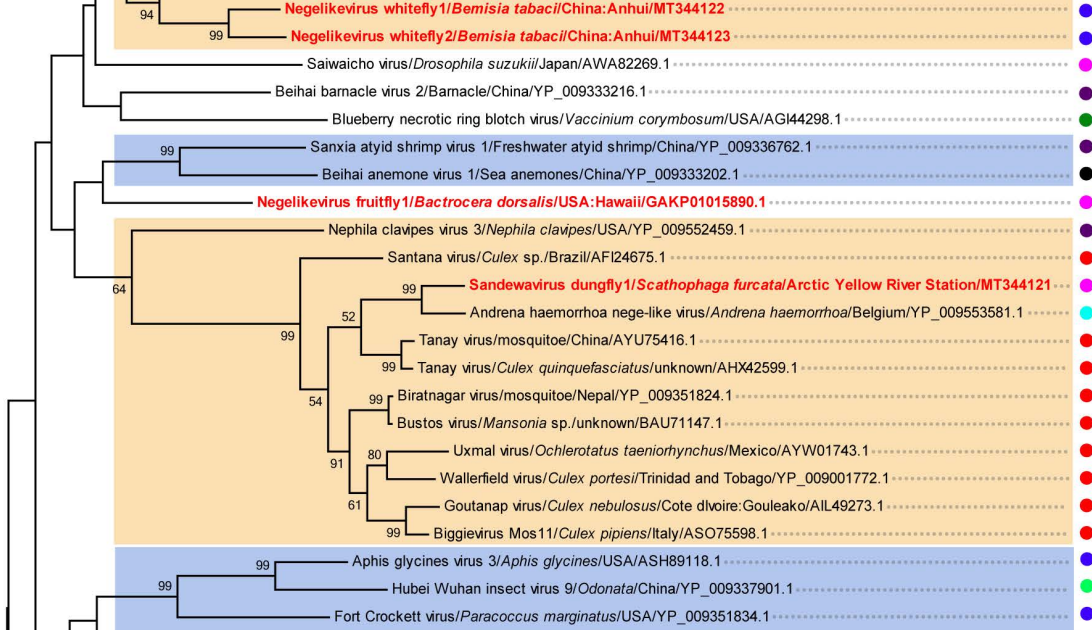

aracoccus marginatus/USA/YP_009351834.

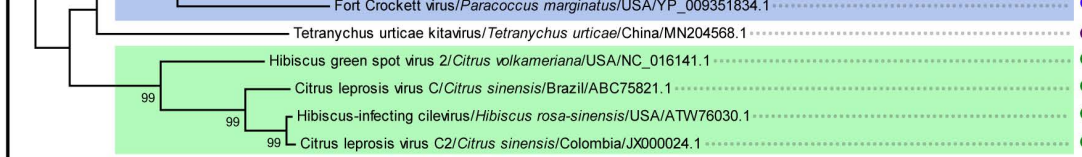

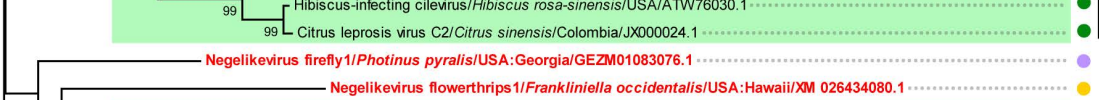
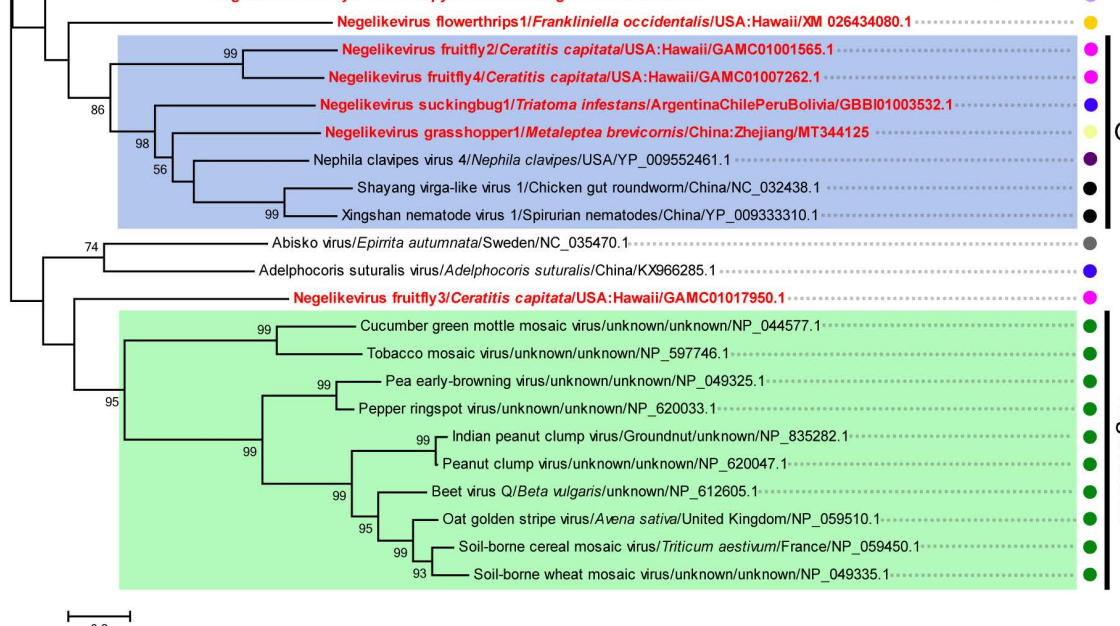

$\longmapsto$

Figure 3. Maximum likelihood phylogenetic tree based on the amino acid sequences of the conserved RdRp domain of the newly identified nege-like viruses from this study, representative negeviruses from various hosts and plant viruses of the families Kitaviridae and Virgaviridae. Branch labels show virus name, virus host, country or origin (region) and corresponding accession numbers. Red font represents nege-like viruses identified in this study. Bootstrap values are placed over each node of the tree (when $>50$ ). Scale bars represent percentage divergence. Taxonomy of the host organism is indicated by circles of different color. 
Table 1. Negevirus-like Contigs identified in other insects from the public database.

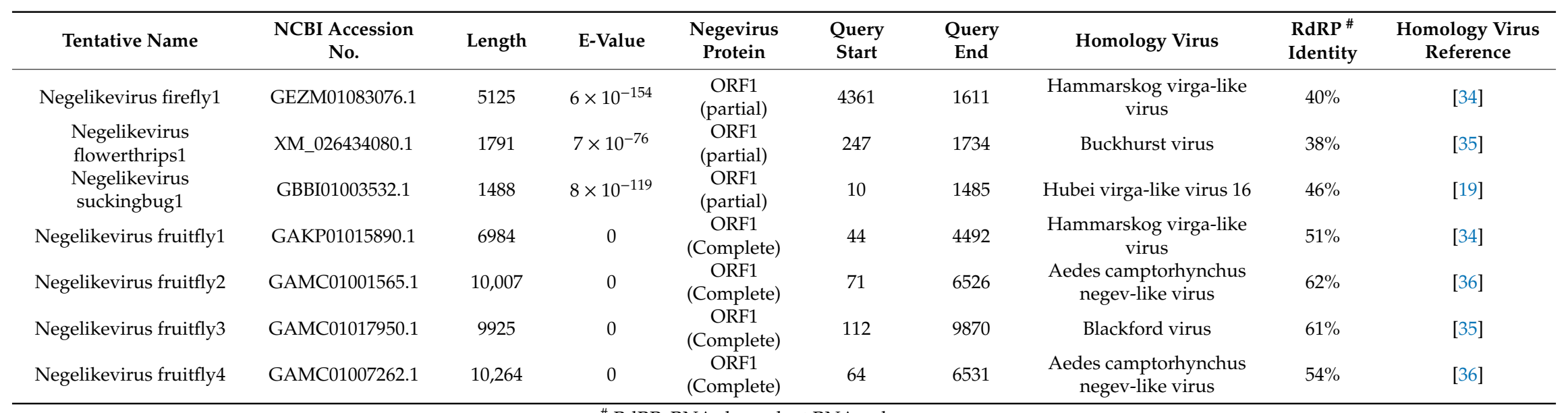

\# RdRP: RNA-dependent RNA polymerase. 
Table 2. Broad host range and wild distribution of nege-like viruses in animals.

\begin{tabular}{|c|c|c|c|c|c|c|c|c|c|}
\hline \multirow{2}{*}{ Virus Name/Tentative Name } & \multicolumn{6}{|c|}{ Host Information } & \multirow{2}{*}{ Location/Year } & \multirow{2}{*}{$\begin{array}{c}\text { GenBank } \\
\text { Accession No. }\end{array}$} & \multirow{2}{*}{ Reference } \\
\hline & Hosts/Species & Phylum & Class & Order & Family & Genus & & & \\
\hline Nelorpivirus dungfly1 & \multirow{2}{*}{ Scathophaga furcata } & \multirow{2}{*}{ Arthropoda } & \multirow{2}{*}{ Insecta } & \multirow{2}{*}{ Diptera } & \multirow{2}{*}{ Scathophagidae } & \multirow{2}{*}{ Scathophaga } & \multirow{2}{*}{$\begin{array}{l}\text { Arctic yellow river } \\
\text { station/2019 }\end{array}$} & MT344120 & \multirow{2}{*}{ This study } \\
\hline Sandewavirus dungfly1 & & & & & & & & MT344121 & \\
\hline Negelikevirus fruitfly1 & Bactrocera dorsalis & Arthropoda & Insecta & Diptera & Tryetidae & Bactrocera & $\begin{array}{l}\text { Puna, Hawaii, } \\
\text { USA/1984 }\end{array}$ & GAKP01015890.1 & [37] \\
\hline Negelikevirus fruitfly2 & \multirow{3}{*}{ Ceratitis capitata } & \multirow{3}{*}{ Arthropoda } & \multirow{3}{*}{ Insecta } & \multirow{3}{*}{ Diptera } & \multirow{3}{*}{ Tephritidae } & \multirow{3}{*}{ Ceratitis } & \multirow{3}{*}{$\begin{array}{l}\text { Waimanalo, Hawaii, } \\
\text { USA/NA }\end{array}$} & GAMC01001565.1 & \multirow{3}{*}{ [38] } \\
\hline Negelikevirus fruitfly3 & & & & & & & & GAMC01017950.1 & \\
\hline Negelikevirus fruitfly4 & & & & & & & & GAMC01007262.1 & \\
\hline Piura virus & Lutzomyia evansi & Arthropoda & Insecta & Diptera & Psychodidae & Lutzomyia & Colombia/2013 & AQS60705.1 & [15] \\
\hline Loreto virus & Lutzomyia sp. & Arthropoda & Insecta & Diptera & Psychodidae & Lutzomyia & Peru/1977 & AFI24693.1 & [5] \\
\hline Saiwaicho virus & Drosophila suzukii & Arthropoda & Insecta & Diptera & Drosophilidae & Drosophila & Japan/2016 & AWA82269.1 & [39] \\
\hline Negelikevirus whitefly1 & \multirow{3}{*}{ Bemisia tabaci } & \multirow{3}{*}{ Arthropoda } & \multirow{3}{*}{ Insecta } & \multirow{3}{*}{ Hemiptera } & \multirow{3}{*}{ Aleyrodidae } & \multirow{3}{*}{ Bemisia } & \multirow{3}{*}{ Anhui, China/2019 } & MT344122 & \multirow{3}{*}{ [33] } \\
\hline Negelikevirus whitefly2 & & & & & & & & MT344123 & \\
\hline Negelikevirus whitefly3 & & & & & & & & МT344124 & \\
\hline Negelikevirus suckingbug1 & Triatoma infestans & Arthropoda & Insecta & Hemiptera & Reduviidae & Triatoma & $\begin{array}{c}\text { Argentina/2007, } \\
\text { Chile/1979, } \\
\text { Peru/2008, } \\
\text { Bolivia/2003-2012 }\end{array}$ & GBBI01003532.1 & [40] \\
\hline Fort Crockett virus & Paracoccus marginatus & Arthropoda & Insecta & Hemiptera & Pseudococcidae & Paracoccus & USA/2015 & YP_009351834.1 & [15] \\
\hline Aphis glycines virus 3 & Aphis glycines & Arthropoda & Insecta & Hemiptera & Aphididae & Aphis & USA/2009 & ASH89118.1 & [41] \\
\hline Adelphocoris suturalis virus & Adelphocoris suturalis & Arthropoda & Insecta & Hemiptera & Miridae & Adelphocoris & China/2015 & KX966285.1 & [42] \\
\hline Negelikevirus firefly1 & Photinus pyralis & Arthropoda & Insecta & Coleoptera & Lampyridae & Photinus & $\begin{array}{c}\text { Lawrenceville, } \\
\text { Georgia, USA/2015 }\end{array}$ & GEZM01083076.1 & [43] \\
\hline Negelikevirus flowerthrips1 & Frankliniella occidentalis & Arthropoda & Insecta & Thysanoptera & Thripidae & Frankliniella & $\begin{array}{l}\text { Oahu, Hawaii, } \\
\text { USA/NA }\end{array}$ & XM_026434080.1 & NA \\
\hline $\begin{array}{l}\text { Andrena haemorrhoa nege-like } \\
\text { virus }\end{array}$ & Andrena haemorrhoa & Arthropoda & Insecta & Hymenoptera & Andrenidae & Andrena & Belgium/2015 & YP_009553581.1 & [18] \\
\hline Hubei Wuhan insect virus 9 & Odonata & Arthropoda & Insecta & Odonata & - & - & China/2013 & YP_009337901.1 & [19] \\
\hline Negelikevirus grasshopper1 & Metaleptea brevicornis & Arthropoda & Insecta & Orthoptera & Acrididae & Metaleptea & $\begin{array}{l}\text { Huzhou, Zhejiang, } \\
\text { China/2019 }\end{array}$ & МТ344125 & [33] \\
\hline Abisko virus & Epirrita autumnata & Arthropoda & Insecta & Lepidoptera & Geometridae & Epirrita & Sweden/2013 & NC_035470.1 & [44] \\
\hline
\end{tabular}


Table 2. Cont.

\begin{tabular}{|c|c|c|c|c|c|c|c|c|c|}
\hline \multirow{2}{*}{ Virus Name/Tentative Name } & \multicolumn{6}{|c|}{ Host Information } & \multirow{2}{*}{ Location/Year } & \multirow{2}{*}{$\begin{array}{c}\text { GenBank } \\
\text { Accession No. }\end{array}$} & \multirow{2}{*}{ Reference } \\
\hline & Hosts/Species & Phylum & Class & Order & Family & Genus & & & \\
\hline Nephila clavipes virus 3 & Nephila clavipes & Arthropoda & Arachnida & Araneae & Nephilidae & Nephila & USA/2013 & YP_009552459.1 & [32] \\
\hline Nephila clavipes virus 4 & Nephila clavipes & Arthropoda & Arachnida & Araneae & Nephilidae & Nephila & USA/2013 & YP_009552461.1 & [32] \\
\hline Tetranychus urticae kitavirus & Tetranychus urticae & Arthropoda & Arachnida & Trombidiformes & Tetranychidae & Tetranychus & China/2018 & MN204568.1 & NA \\
\hline Sanxia atyid shrimp virus 1 & $\begin{array}{c}\text { Freshwater atyid } \\
\text { shrimp }\end{array}$ & Arthropoda & Malacostraca & Decapoda & Atyidae & - & China/2014 & YP_009336762.1 & [19] \\
\hline Beihai barnacle virus 2 & Barnacle & Arthropoda & Maxillopoda & - & - & - & China/2014 & YP_009333216.1 & [19] \\
\hline Wuhan house centipede virus 1 & Scutigera coleoptrata & Arthropoda & Chilopoda & Scutigeromorpha & Scutigeridae & Scutigera & China/2013 & YP_009342435.1 & [19] \\
\hline Shayang virga-like virus 1 & $\begin{array}{l}\text { Chicken gut } \\
\text { roundworm }\end{array}$ & Nematode & Secernentea & Ascaridida & Ascaridiidae & - & China/2014 & NC_032438.1 & [19] \\
\hline Xingshan nematode virus 1 & Spirurian nematodes & Nematode & Chromadorea & Rhabditida & - & - & China/2014 & YP_009333310.1 & [19] \\
\hline Beihai anemone virus 1 & Sea anemones & Cnidaria & Anthozoa & Actiniaria & - & - & China/2014 & YP_009333202.1 & [19] \\
\hline
\end{tabular}




\section{Discussion}

Since the taxon Negevirus was initially suggested, more than 100 negeviruses have been isolated worldwide, particularly from in Asia, Africa, Oceania, Europe and America [15]. All previously discovered negeviruses were from the tropical, sub-tropical and temperate regions (latitudes between $42^{\circ} \mathrm{N}$ and $42^{\circ} \mathrm{S}$ ), raising the possibility that negeviruses might be affected significantly by environmental factors and not be adapted to hosts living in extreme conditions such as low temperature [16]. In this study, two new negeviruses (NVD1 and SVD1) were identified in a dungfly (S. furcata) collected from the arctic region (latitude $79^{\circ} \mathrm{N}$ ), much further north than any previously described negevirus. Earlier work suggested that negeviruses from different clades might be found in the same host and geographic location [15]. This is supported and extended by our finding of two negeviruses from different clades (NVD1-Nelorpivirus, SVD1-Sandewavirus) within single individual host insect.

Negeviruses are also well-known for having a broad host range among biting Diptera, including nine genera of mosquitoes, that have been studied because of their importance to public health $[3,5,15]$. The viruses reported here and the subsequent in silico studies of public databases and published virome data show that the hosts of nege-like viruses are much more diverse. Known hosts now include insects belonging to the orders Diptera, Hemiptera, Coleoptera, Thysanoptera, Hymenoptera, Odonata, Orthoptera, and Lepidoptera and, interestingly, non-insect arthropods (spider, shrimp etc.) and even non-arthropod organisms (nematodes and anemone) (Table 2). These results provide strong evidence to support the previous hypothesis that the host range of negeviruses might have been greatly underestimated due to current sampling bias in favor of biting or blood-sucking arthropods [5,15]. It is clearly no longer tenable to regard negeviruses as insect-specific or mosquito-specific viruses.

Phylogenetic studies and the discovery of Insect-specific viruses (ISV) genomic material integrated into the mosquito genome have led to the hypothesis that a number of pathogenic arboviruses may have acquired their dual host through long term adaptive evolution of former ISVs in vertebrates $[20,45]$. Negeviruses are genetically and evolutionarily related to plant viruses in the family Kitaviridae $[5,6,17]$, and investigation of endogenous viral elements indicated that virga/nege-related viruses in insects and plants might share common viral origins [46]. Our phylogenetic analysis indicated that three nege-like viruses in the unassigned group 1 and Tetranychus urticae kitavirus are phylogenetically closer to plant viruses (Kitaviridae), filling the phylogenetic "gaps" between plant-associated viruses and the proposed two clades of negeviruses (Figure 3). Interestingly, a newly reported nege-like virus (Fragaria vesca-associated virus 1) isolated from a symptomatic strawberry plant also shows high homology to Aphis glycines virus 3 [47], indicating that this unassigned group might be the key connection between nege-related arthropod viruses and plant viruses. The increasing number of newly discovered nege-like viruses will surely help to clarify the uncertain relationship between nege-like viruses and associated plant viruses. The phylogenetic relationships of some nege-like viruses in the tree were incongruent with host phylogeny, especially for the viruses in the three unassigned groups (Figure 3), indicating the possibility of cross-species virus transmission in a similar ecological niche.

The high numbers of viral transcripts of NVD1 $(6858 \times)$ and SDV1 $(8857 \times)$ in S. furcata show that the viruses were infecting and propagating in the insect and were not just contaminants. Previous studies have shown that negeviruses can replicate to high viral loads in cell lines of some mosquitoes and sandflies [5,15]. In addition, dsRNA intermediates of negeviruses can be detected in mosquito C6/36 cells in early stages of infection, indicating that this replication may use a dsRNA intermediate [9]. In this study, we detected and characterized vsiRNAs derived from both NVD1 and SDV1 in S. furcata. These were mostly $21 \mathrm{nt}$ long and were more or less equally derived from both strands of the dsRNA replication intermediates, providing clear evidence that negeviruses are targeted by the host siRNA-based antiviral RNAi pathway. It will be interesting to investigate whether negeviruses can induce similar siRNA-based antiviral immunity in non-insect hosts in the future. Several studies have shown that infection by some strains of Wolbachia can upregulate the mosquito's innate immune system and then interfere with mosquito-borne virus replication by decreasing vector competence $[48,49]$. In addition, laboratory experiments have also indicated that insect-specific 
flaviviruses can downregulate the replication of heterologous flaviviruses in mosquito cells [50,51]. Since negeviruses can replicate actively in several well-known arthropod vectors of vertebrate viruses (mosquitoes, sandflies) and plant viruses (aphids, whiteflies), it will be fascinating to evaluate the impact of negevirus replication on the fitness and vector competence of these important arbovirus vectors. It is at least possible that, if true, negeviruses could have enormous potential value as biological control agents of pathogenic viruses.

Supplementary Materials: Available online: http://www.mdpi.com/1999-4915/12/7/692/s1. Table S1: Representative negeviruses used for the identification of nege-like viral contigs; Table S2: Primers used in this study.

Author Contributions: Conceptualization, J.-P.C., C.-X.Z. and J.-M.L.; methodology, G.L. and Z.-X.Y.; validation, G.L., Y.-J.H., Y.Z. and X.W.; formal analysis, Z.-X.Y., H.-J.H., J.-C.Z. and Z.-T.S.; investigation, G.L., Z.-T.S. and F.Y.; data curation, G.L., Z.-X.Y. and Y.-J.H.; writing-original draft preparation, J.-P.C., C.-X.Z. and -J.-M.L.; writing - review and editing, J.-P.C., C.-X.Z. and J.-M.L.; supervision, J.-M.L.; project administration, J.-P.C.; funding acquisition, J.-P.C. All authors have read and agreed to the published version of the manuscript.

Funding: This research was funded by [the China National Novel Transgenic Organisms Breeding Project] grant number [2019ZX08004-004], [the National Key R\&D Program of China] grant number [2016YFD0200804], [Ningbo Science and Technology Innovation 2025 Major Project] grant number [2019B10004], and [the National Key R\&D Program of China] grant number [2016YFD0300706]. And the APC was funded by [the China National Novel Transgenic Organisms Breeding Project] grant number [2019ZX08004-004]. This work was sponsored by K.C.Wong Magna Fund in Ningbo University.

Acknowledgments: The dungfly sample was kindly collected and provided by the organization of Polar Young Pioneers and International Polar Protection Association. We thank Mike J. Adams (Minehead, UK) for his valuable and constructive suggestions for improving the manuscript.

Conflicts of Interest: The authors declare no conflicts of interest.

\section{References}

1. Vasilakis, N.; Tesh, R.B. Insect-specific viruses and their potential impact on arbovirus transmission. Curr. Opin. Virol. 2015, 15, 69-74. [CrossRef] [PubMed]

2. Junglen, S.; Drosten, C. Virus discovery and recent insights into virus diversity in arthropods. Curr. Opin. Microbiol. 2013, 16, 507-513. [CrossRef] [PubMed]

3. Bolling, B.G.; Weaver, S.C.; Tesh, R.B.; Vasilakis, N. Insect-Specific Virus Discovery: Significance for the Arbovirus Community. Viruses 2015, 7, 4911-4928. [CrossRef] [PubMed]

4. Marklewitz, M.; Zirkel, F.; Kurth, A.; Drosten, C.; Junglen, S. Evolutionary and phenotypic analysis of live virus isolates suggests arthropod origin of a pathogenic RNA virus family. Proc. Natl. Acad. Sci. USA 2015, 112, 7536-7541. [CrossRef] [PubMed]

5. Vasilakis, N.; Forrester, N.L.; Palacios, G.; Nasar, F.; Savji, N.; Rossi, S.L.; Guzman, H.; Wood, T.G.; Popov, V.; Gorchakov, R.; et al. Negevirus: A proposed new taxon of insect-specific viruses with wide geographic distribution. J. Virol. 2013, 87, 2475-2488. [CrossRef]

6. Kallies, R.; Kopp, A.; Zirkel, F.; Estrada, A.; Gillespie, T.R.; Drosten, C.; Junglen, S. Genetic characterization of goutanap virus, a novel virus related to negeviruses, cileviruses and higreviruses. Viruses 2014, 6, 4346-4357. [CrossRef]

7. Kawakami, K.; Kurnia, Y.W.; Fujita, R.; Ito, T.; Isawa, H.; Asano, S.; Binh, N.D.; Bando, H. Characterization of a novel negevirus isolated from Aedes larvae collected in a subarctic region of Japan. Arch. Virol. 2016, 161, 801-809. [CrossRef]

8. Kuchibhatla, D.B.; Sherman, W.A.; Chung, B.Y.; Cook, S.; Schneider, G.; Eisenhaber, B.; Karlin, D.G. Powerful sequence similarity search methods and in-depth manual analyses can identify remote homologs in many apparently "orphan" viral proteins. J. Virol. 2014, 88, 10-20. [CrossRef]

9. Carapeta, S.; do Bem, B.; McGuinness, J.; Esteves, A.; Abecasis, A.; Lopes, A.; de Matos, A.P.; Piedade, J.; de Almeida, A.P.; Parreira, R. Negeviruses found in multiple species of mosquitoes from southern Portugal: Isolation, genetic diversity, and replication in insect cell culture. Virology 2015, 483, 318-328. [CrossRef]

10. Zhang, W.; Gu, Q.; Niu, J.; Wang, J.J. The RNA Virome and Its Dynamics in an Invasive Fruit Fly, Bactrocera dorsalis, Imply Interactions Between Host and Viruses. Microb. Ecol. 2020, 1-12. [CrossRef] 
11. Nabeshima, T.; Inoue, S.; Okamoto, K.; Posadas-Herrera, G.; Yu, F.; Uchida, L.; Ichinose, A.; Sakaguchi, M.; Sunahara, T.; Buerano, C.C.; et al. Tanay virus, a new species of virus isolated from mosquitoes in the Philippines. J. Gen. Virol. 2014, 95 Pt 6, 1390-1395. [CrossRef]

12. Wang, J.; Wu, J.; Li, N.; Cao, Y.; He, Y.; Lin, J.; Li, H. A new Tanay virus isolated from mosquitoes in Guangxi, China. Arch. Virol. 2018, 163, 3177-3180. [CrossRef] [PubMed]

13. O’Brien, C.A.; McLean, B.J.; Colmant, A.M.G.; Harrison, J.J.; Hall-Mendelin, S.; van den Hurk, A.F.; Johansen, C.A.; Watterson, D.; Bielefeldt-Ohmann, H.; Newton, N.D.; et al. Discovery and Characterisation of Castlerea Virus, a New Species of Negevirus Isolated in Australia. Evol. Bioinform. 2017, 13, 1176934317691269.

14. Auguste, A.J.; Carrington, C.V.; Forrester, N.L.; Popov, V.L.; Guzman, H.; Widen, S.G.; Wood, T.G.; Weaver, S.C.; Tesh, R.B. Characterization of a novel Negevirus and a novel Bunyavirus isolated from Culex (Culex) declarator mosquitoes in Trinidad. J. Gen. Virol. 2014, 95 Pt 2, 481-485. [CrossRef]

15. Nunes, M.R.T.; Contreras-Gutierrez, M.A.; Guzman, H.; Martins, L.C.; Barbirato, M.F.; Savit, C.; Balta, V.; Uribe, S.; Vivero, R.; Suaza, J.D.; et al. Genetic characterization, molecular epidemiology, and phylogenetic relationships of insect-specific viruses in the taxon Negevirus. Virology 2017, 504, 152-167. [CrossRef] [PubMed]

16. Zhao, L.; Mwaliko, C.; Atoni, E.; Wang, Y.; Zhang, Y.; Zhan, J.; Hu, X.; Xia, H.; Yuan, Z. Characterization of a Novel Tanay Virus Isolated From Anopheles sinensis Mosquitoes in Yunnan, China. Front. Microbiol. 2019, 10, 1963. [CrossRef]

17. Ramos-Gonzalez, P.L.; Dos Santos, G.F.; Chabi-Jesus, C.; Harakava, R.; Kitajima, E.W.; Freitas-Astua, J. Passion Fruit Green Spot Virus Genome Harbors a New Orphan ORF and Highlights the Flexibility of the 5'-End of the RNA2 Segment Across Cileviruses. Front. Microbiol. 2020, 11, 206. [CrossRef]

18. Schoonvaere, K.; Smagghe, G.; Francis, F.; de Graaf, D.C. Study of the Metatranscriptome of Eight Social and Solitary Wild Bee Species Reveals Novel Viruses and Bee Parasites. Front. Microbiol. 2018, 9, 177. [CrossRef]

19. Shi, M.; Lin, X.D.; Tian, J.H.; Chen, L.J.; Chen, X.; Li, C.X.; Qin, X.C.; Li, J.; Cao, J.P.; Eden, J.S.; et al. Redefining the invertebrate RNA virosphere. Nature 2016, 540, 539-543. [CrossRef]

20. Li, C.X.; Shi, M.; Tian, J.H.; Lin, X.D.; Kang, Y.J.; Chen, L.J.; Qin, X.C.; Xu, J.; Holmes, E.C.; Zhang, Y.Z. Unprecedented genomic diversity of RNA viruses in arthropods reveals the ancestry of negative-sense RNA viruses. elife 2015, 4, e05378. [CrossRef]

21. Grabherr, M.G.; Haas, B.J.; Yassour, M.; Levin, J.Z.; Thompson, D.A.; Amit, I.; Adiconis, X.; Fan, L.; Raychowdhury, R.; Zeng, Q.; et al. Full-length transcriptome assembly from RNA-Seq data without a reference genome. Nat. Biotechnol. 2011, 29, 644-652. [CrossRef] [PubMed]

22. Li, J.; Andika, I.B.; Shen, J.; Lv, Y.; Ji, Y.; Sun, L.; Chen, J. Characterization of rice black-streaked dwarf virusand rice stripe virus-derived siRNAs in singly and doubly infected insect vector Laodelphax Striatellus. PLoS ONE 2013, 8, e66007. [CrossRef] [PubMed]

23. Langmead, B.; Salzberg, S.L. Fast gapped-read alignment with Bowtie 2. Nat. Methods 2012, 9, $357-359$. [CrossRef] [PubMed]

24. Li, H.; Handsaker, B.; Wysoker, A.; Fennell, T.; Ruan, J.; Homer, N.; Marth, G.; Abecasis, G.; Durbin, R. The Sequence Alignment/Map format and SAMtools. Bioinformatics 2009, 25, 2078-2079. [CrossRef] [PubMed]

25. Thorvaldsdottir, H.; Robinson, J.T.; Mesirov, J.P. Integrative Genomics Viewer (IGV): High-performance genomics data visualization and exploration. Brief. Bioinform. 2013, 14, 178-192. [CrossRef]

26. Marchler-Bauer, A.; Bo, Y.; Han, L.; He, J.; Lanczycki, C.J.; Lu, S.; Chitsaz, F.; Derbyshire, M.K.; Geer, R.C.; Gonzales, N.R.; et al. CDD/SPARCLE: Functional classification of proteins via subfamily domain architectures. Nucleic Acids Res. 2017, 45, D200-D203. [CrossRef]

27. Langmead, B.; Trapnell, C.; Pop, M.; Salzberg, S.L. Ultrafast and memory-efficient alignment of short DNA sequences to the human genome. Genome Biol. 2009, 10, R25. [CrossRef]

28. Edgar, R.C. MUSCLE: Multiple sequence alignment with high accuracy and high throughput. Nucleic Acids Res. 2004, 32, 1792-1797. [CrossRef]

29. Kumar, S.; Stecher, G.; Li, M.; Knyaz, C.; Tamura, K. MEGA X: Molecular Evolutionary Genetics Analysis across Computing Platforms. Mol. Biol. Evol. 2018, 35, 1547-1549. [CrossRef]

30. Ding, S.W.; Voinnet, O. Antiviral immunity directed by small RNAs. Cell 2007, 130, 413-426. [CrossRef]

31. Mi, S.; Cai, T.; Hu, Y.; Chen, Y.; Hodges, E.; Ni, F.; Wu, L.; Li, S.; Zhou, H.; Long, C. Sorting of Small RNAs into Arabidopsis Argonaute Complexes Is Directed by the 5' Terminal Nucleotide. Cell 2008, 133, $116-127$. [CrossRef] [PubMed] 
32. Debat, H.J. An RNA Virome Associated to the Golden Orb-Weaver Spider Nephila clavipes. Front. Microbiol. 2017, 8, 2097. [CrossRef] [PubMed]

33. Ye, Z.X.; Huang, H.J.; Lu, G.; Zhuo, J.C.; Chen, J.P.; Zhang, C.X.; Li, J.M. Virome analysis of whitefly collected from Anhui, China. Manuscript in preparation.

34. Ohlund, P.; Hayer, J.; Lunden, H.; Hesson, J.C.; Blomstrom, A.L. Viromics Reveal a Number of Novel RNA Viruses in Swedish Mosquitoes. Viruses 2019, 11, 1027. [CrossRef] [PubMed]

35. Webster, C.L.; Longdon, B.; Lewis, S.H.; Obbard, D.J. Twenty-Five New Viruses Associated with the Drosophilidae (Diptera). Evol. Bioinform. 2016, 12 (Suppl. 2), 13-25. [CrossRef]

36. Shi, M.; Neville, P.; Nicholson, J.; Eden, J.S.; Imrie, A.; Holmes, E.C. High-Resolution Metatranscriptomics Reveals the Ecological Dynamics of Mosquito-Associated RNA Viruses in Western Australia. J. Virol. 2017, 91. [CrossRef]

37. Geib, S.M.; Calla, B.; Hall, B.; Hou, S.; Manoukis, N.C. Characterizing the developmental transcriptome of the oriental fruit fly, Bactrocera dorsalis (Diptera: Tephritidae) through comparative genomic analysis with Drosophila melanogaster utilizing modENCODE datasets. BMC Genom. 2014, 15, 942. [CrossRef]

38. Calla, B.; Hall, B.; Hou, S.; Geib, S.M. A genomic perspective to assessing quality of mass-reared SIT flies used in Mediterranean fruit fly (Ceratitis capitata) eradication in California. BMC Genom. 2014, 15, 98. [CrossRef]

39. Medd, N.C.; Fellous, S.; Waldron, F.M.; Xuereb, A.; Nakai, M.; Cross, J.V.; Obbard, D.J. The virome of Drosophila suzukii, an invasive pest of soft fruit. Virus Evol. 2018, 4, vey009. [CrossRef]

40. Schwarz, A.; Medrano-Mercado, N.; Schaub, G.A.; Struchiner, C.J.; Bargues, M.D.; Levy, M.Z.; Ribeiro, J.M. An updated insight into the Sialotranscriptome of Triatoma infestans: Developmental stage and geographic variations. PLoS Negl. Trop. Dis. 2014, 8, e3372. [CrossRef]

41. Feng, Y.; Krueger, E.N.; Liu, S.; Dorman, K.; Bonning, B.C.; Miller, W.A. Discovery of known and novel viral genomes in soybean aphid by deep sequencing. Phytobiomes 2017, 1, 36-45. [CrossRef]

42. Li, X.; Xu, P.; Yang, X.; Yuan, H.; Chen, L.; Lu, Y. The genome sequence of a novel RNA virus in Adelphocoris suturalis. Arch. Virol. 2017, 162, 1397-1401. [CrossRef] [PubMed]

43. Al-Wathiqui, N.; Fallon, T.R.; South, A.; Weng, J.K.; Lewis, S.M. Molecular characterization of firefly nuptial gifts: A multi-omics approach sheds light on postcopulatory sexual selection. Sci. Rep. 2016, 6, 38556. [CrossRef] [PubMed]

44. De Miranda, J.R.; Hedman, H.; Onorati, P.; Stephan, J.; Karlberg, O.; Bylund, H.; Terenius, O. Characterization of a novel RNA virus discovered in the autumnal moth Epirrita autumnata in Sweden. Viruses 2017, 9, 214. [CrossRef]

45. Roundy, C.M.; Azar, S.R.; Rossi, S.L.; Weaver, S.C.; Vasilakis, N. Insect-Specific Viruses: A Historical Overview and Recent Developments. Adv. Virus Res. 2017, 98, 119-146. [PubMed]

46. Kondo, H.; Chiba, S.; Maruyama, K.; Andika, I.B.; Suzuki, N. A novel insect-infecting virga/nege-like virus group and its pervasive endogenization into insect genomes. Virus Res. 2019, 262, 37-47. [CrossRef]

47. Lenz, O.; Pribylova, J.; Franova, J.; Koloniuk, I. Fragaria vesca-associated virus 1, a new virus related to negeviruses. Arch. Virol. 2020, 165, 1249-1252. [CrossRef]

48. Moreira, L.A.; Iturbe-Ormaetxe, I.; Jeffery, J.A.; Lu, G.; Pyke, A.T.; Hedges, L.M.; Rocha, B.C.; Hall-Mendelin, S.; Day, A.; Riegler, M.; et al. A Wolbachia symbiont in Aedes aegypti limits infection with dengue, Chikungunya, and Plasmodium. Cell 2009, 139, 1268-1278. [CrossRef]

49. Rances, E.; Ye, Y.H.; Woolfit, M.; McGraw, E.A.; O'Neill, S.L. The relative importance of innate immune priming in Wolbachia-mediated dengue interference. PLoS Pathog 2012, 8, e1002548. [CrossRef]

50. Hobson-Peters, J.; Yam, A.W.Y.; Lu, J.W.F.; Setoh, Y.X.; May, F.J.; Kurucz, N.; Walsh, S.; Prow, N.A.; Davis, S.S.; Weir, R. A new insect-specific flavivirus from northern Australia suppresses replication of West Nile virus and Murray Valley encephalitis virus in co-infected mosquito cells. PLoS ONE 2013, 8, e56534. [CrossRef]

51. Kenney, J.L.; Solberg, O.D.; Langevin, S.A.; Brault, A.C. Characterization of a novel insect-specific flavivirus from Brazil: Potential for inhibition of infection of arthropod cells with medically important flaviviruses. $J$. Gen. Virol. 2014, 95 Pt 12, 2796-2808. [CrossRef]

(C) 2020 by the authors. Licensee MDPI, Basel, Switzerland. This article is an open access article distributed under the terms and conditions of the Creative Commons Attribution (CC BY) license (http://creativecommons.org/licenses/by/4.0/). 